\title{
DEVELOPING HOLISTIC ENGINEERING COMPETENCIES IN A BIO- INSPIRED DESIGN COURSE
}

\author{
Marjan Eggermont and Robyn Paul \\ Schulich School of Engineering, University of Calgary \\ meggermo@ucalgary.ca,rmpaul@ucalgary.ca
}

\begin{abstract}
Bio-inspired design can be found in an increasing number of products and applications from surgical staples inspired by porcupines to bacteria inhibiting foil inspired by sharks. As a methodology, bioinspired design studies nature, its models, systems, and processes and then imitates or takes creative inspiration from them to solve human problems often sustainably. Bioinspired design as a methodology is applicable to multiple disciplines and has driven innovations in fields ranging from business to engineering. The increase in interest in this method of design comes directly from our search for sustainable solutions to solving problems. A recent technical elective explores this design methodology to increase a holistic view of design using project-based learning in a community context.
\end{abstract}

Keywords: Bio-inspired design, holistic engineering competencies, community projects.

\section{INTRODUCTION}

Engineering work is continually evolving to be more cross-disciplinary and require stronger attention to factors such as sustainability and social justice [1,2]. As engineering educators, it is thus our responsibility to support student learning of design to be holistic and crossdisciplinary. In a 2017 article, Grasso and Martinelli described holistic engineering as follows: "In engineering, a discipline that purports to design for humanity and improve the quality of life, the unity of knowledge should be a sine qua non that asks engineers to look outward, beyond the fields of math and science, in search of solutions to entire problems. To better serve humanity, engineers must at least attempt to understand the human condition in all its complexity - which requires the study of literature, history, philosophy, psychology, religion, and economics, among other fields." [3] Bio-inspired design as a pedagogical approach has been successful in bridging students to develop some of these competencies and to approach design and problem solving with a wider lens [4,5].

A new technical elective, ENGG 523 Bio-inspired Design, explores the principles and systems behind evolved natural constructions and processes, and transfers these to device and system design: abstractions of functional morphologies leading to new technical concepts and prototypes. Topics in this course include design by analogy, functional morphology, bio-inspired design methods, technical sketching, and bio-inspired computation and modelling to name a few. The course is a combination of workshops and design process exercises to support two concurrent projects.

This 'practice' paper discusses the pedagogical approach to the course and the importance of real-world challenges and learning outside the classroom through a community project. Project components start as individual assignments and students form groups towards the end of the term based on area of interest, research, and affinity. The first project is a collaboration with our local zoo. Students will present their project solutions and ideas to a K-6 spring zoo camp towards the end of the semester.

The second project is participation in a global biomimicry design challenge with the goal of designing solutions to climate change problems that aid one or more Sustainable Development Goal. Solutions developed for this project are submitted to the challenge and evaluated by a team of international judges.

Overall, this paper provides insight into the design and implementation of the bio-inspired design course as a tool to support student learning of holistic engineering competencies through a community-based project.

\section{THE CONTEXT}

$$
\begin{aligned}
& \text { "The trouble is that once you see it, } \\
& \text { you can't unsee it. And once you've } \\
& \text { seen it, keeping quiet, saying } \\
& \text { nothing, becomes as political an act } \\
& \text { as speaking out. There's no } \\
& \text { innocence. Either way, you're } \\
& \text { accountable." - Arundhati Roy }
\end{aligned}
$$

Engineering can take inspiration from nature to develop new products, processes, and systems, or improve existing designs [4]. It also changes the relationship students have with nature and organisms. We are often taught what we know about organisms when we are younger, but not what we can learn from organisms. We are coming out of the machine and information age and moving into the biology 
age. This is partially because technology has become sophisticated enough to allow us insight into the biology and partially because we understand now that conquering nature is an ill-advised pursuit. The trick is to co-exist with and learn from nature and to understand that we are nature ourselves.

Bio-inspired design can be used to inspire students, and to foster the necessary engineering graduate attributes in our students [5]. Undergraduate engineering students are excited by the possibilities and see that there is still a great deal to be invented and improved, and that they can make a real change in the world.

One of the authors has taught bio-inspired design since 2004 to over 10,000 students in corner- and capstone courses through projects ranging from workshops, oneweek paper-based deliverables to multi-week prototyped design concepts. ENGG 523 is a new technical elective devoted entirely to this design methodology, available to be taken by students in most of our engineering programs. Topics in this course include design by analogy, functional biology, principles and techniques of biomimicry, bioinspired engineering methods, and bio-inspired computation. The course has the following learning outcomes:

- Develop an understanding of biomimetics: test key concepts employed in biomimicry through the experience of creating novel biomimetic projects.

- Identify opportunities through biomimetics: abstracting from nature to generate functional processes and models.

- Understand an artifact, product, or system functionally during a concept or ideation design phase.

- Generate and evaluate alternatives using morphological charts and evaluation techniques.

- Observe, research, sketch, and create 3D models while generating biomimetic prototypes.

Students gain experience and a working knowledge of ideation, concept development and model and create a bioinspired engineering project. Using projects as one of the core course activities (commonly known as project-based learning, or PBL), is a pedagogy that has been shown to enhance technical and professional skill development in engineering [6]. A recent literature review of PBL found six key recommendations in order to ensure effective and successful implementation of PBL [7]:

1. Student support

2. Teaching support

3. Effective group work

4. Balancing didactic instruction with independent inquiry method

5. Assessment emphasis on reflection, self and peer evaluation

6. An element of student choice and autonomy
In the next section, we outline the two main projects of the course, and the different elements of the PBL learning experiences.

\section{THE PROJECTS}

In the second iteration of the bio-inspired design technical elective course, a cyclical design process is the thread through the term. In bio-inspired design, two approaches are common: the biology to design pathway and the challenge to biology pathway.

Biology to design is considered to be "solutions-based", where we are inspired from biology and use this idea for a design [8]. A famous biology to design example is Velcro: Swiss engineer George de Mestral went hiking with his dog in the mid-1940s. While pulling burdock seeds out of the dog's fur, he realized the hooked barbs of the seed combined with the dog hair could be a model for a new type of hook and loop fastener [9].

The challenge to biology approach, considered "problem-based", starts with a problem or challenge and then looks to biology for inspiration and strategies (i.e. how an organism solves a problem or achieves a specific function) [8]. The course includes two main projects, which takes students through both design approaches.

\subsection{The Zoo Project: Biology to Design}

The Calgary Zoo project is a biology to design project. As part of this project, we scheduled a lab in the invertebrate zoology area on our campus and students spent three hours sketching biological specimens. As part of the sketching lab they also worked with the pattern alphabet developed by Alex Wolf from na2ure [10] (see Fig. 1). In addition to sketching specimens, they also had to look out for dominant patterns that can be found in nature. For example, patterns such as branching (or fractals) can be useful in design and encourage students to think about concepts such as self-similarity. Asymmetry, mating symmetry, mirror symmetry, and bi-lateral symmetry are all interesting ways to think about manufacturing, packaging, and optimizing packing and shipping [4].

Two weeks following the sketching activity, we went on a tour of the Calgary Zoo. Students were guided through three of the zoo's habitats and they each picked an organism seen on the tour. Students had to find out everything there is to know about their chosen organism from historical stories to fables to early scientific literature to 'use' to recent research that describes what we can learn from the organisms. Zoos in general have information about plants and animals but often the most inspiring material, the design strategies that can be learned from the species, is missing from the zoo's informational material. To illustrate the extent of information that can be gathered, we showed two examples to the students. 

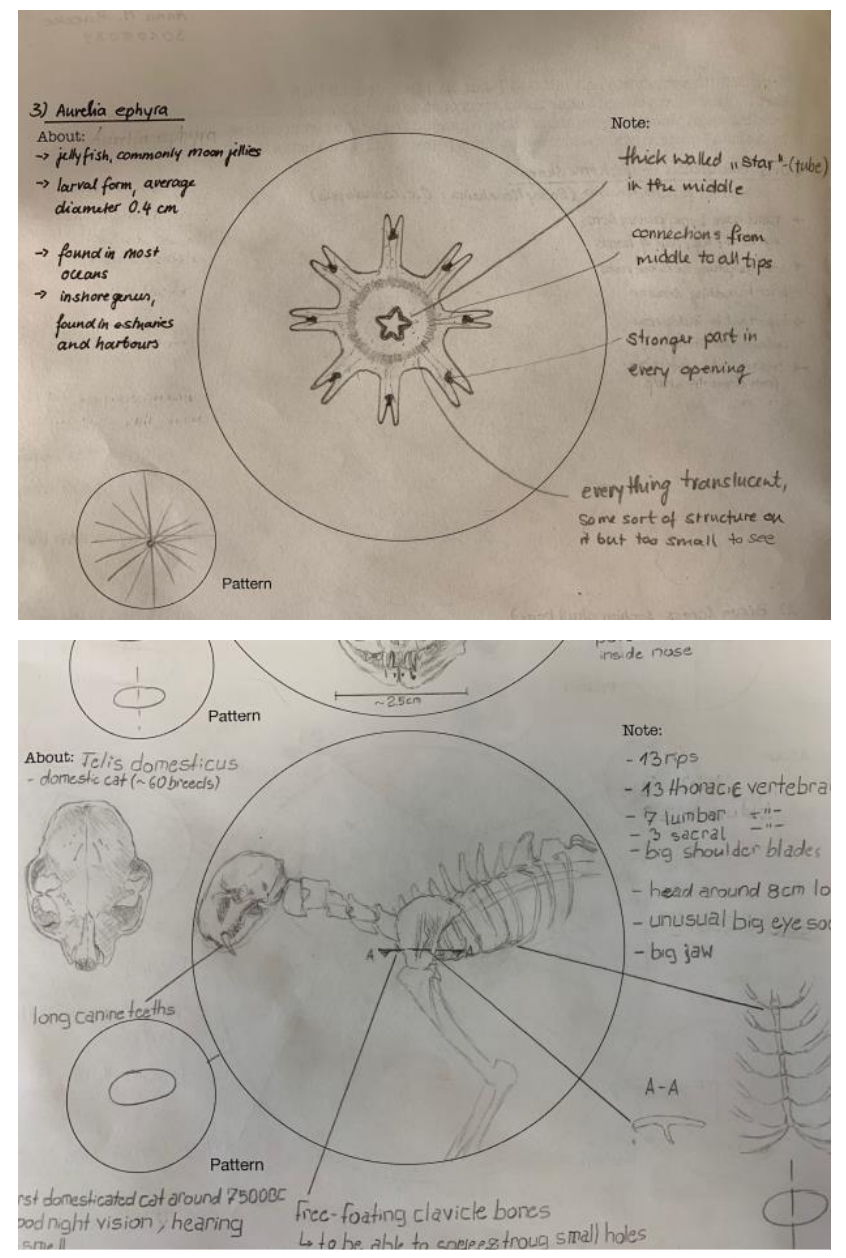

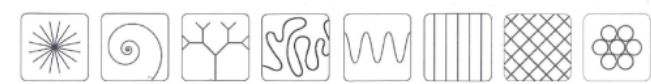

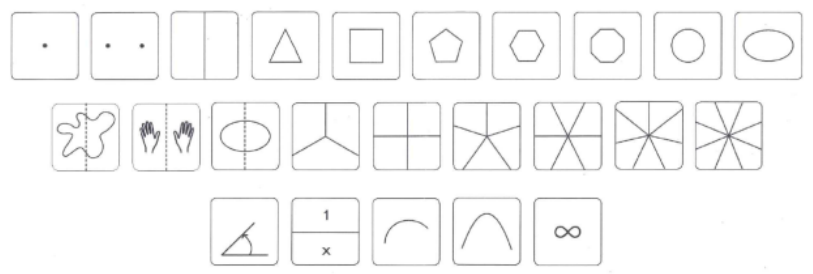

Fig. 1. Student work by Anna Baecke and Stephanie Weckesser and the Pattern Alphabet [9].

Firstly, Christien Meindertsma's book "Pig 05049" chronicles the many consumer products that were made from a pig called 05049 (Fig. 2) [11]. The book offers an insightful look into how this one animal, a single source, provides raw material for a vast number of everyday objects. Organised by body part, the book follows the progress of the dissection of Pig 05049 and the subsequent use of each part. Some products, she found, are expected and familiar whilst other diverge dramatically, such as: ammunition, medicine, photo paper, cigarettes, conditioner and bio diesel [11].” This is not a standard approach for bio-inspired design. However, in order to have a full picture of our past and present attitudes and 'uses' of organisms it is important to have a big picture view.

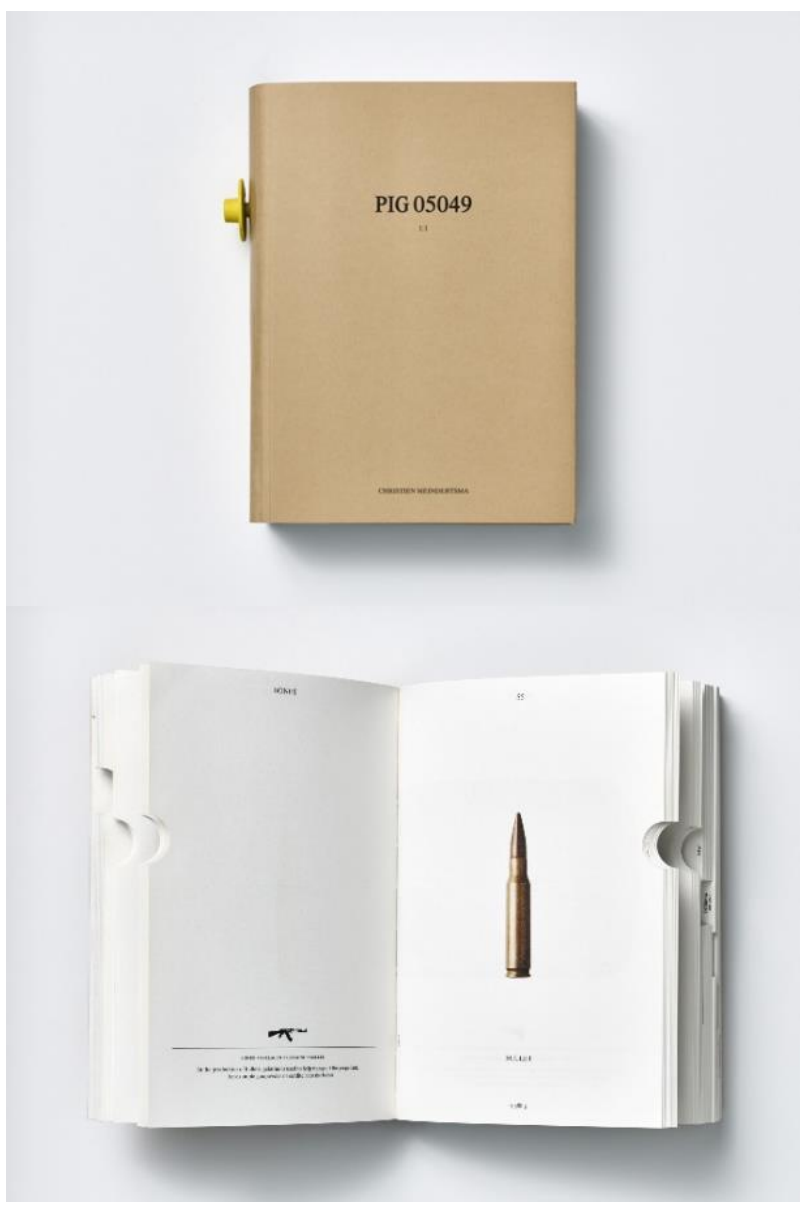

Fig. 2. PIG 05049 and a 'use' example: gelatine to help transport propellant into a bullet [11].

A second example of the depth and variety of information we can gather from one organism, is that of the stories surrounding beavers. A depiction from an Egyptian hieroglyphic was adopted into Aesop's fables and continued well into the $17_{\text {th }}$ century. The fable says that in order to live when chased by hunters, beavers chew off their scrotum. Hunted for their anal scent glands - believed to have healing powers - and beaver fur, beavers were hunted close to extinction. However, the anatomy of beavers was not well understood: beavers do not have a scrotum external to their bodies and on top of that, it resembled the glands they were hunted for. The glands contain castoreum, which is to this day used in 'leathery' perfumes, raspberry ice cream, and a Swedish liquor called 'Beavershout', among other things. In the 18th century, beavers were thought to operate as bee colonies, as communities of social rodents happily constructing communal dams with a foreman, architects, and workers (even exhausted ones, Figure 3 detail). 


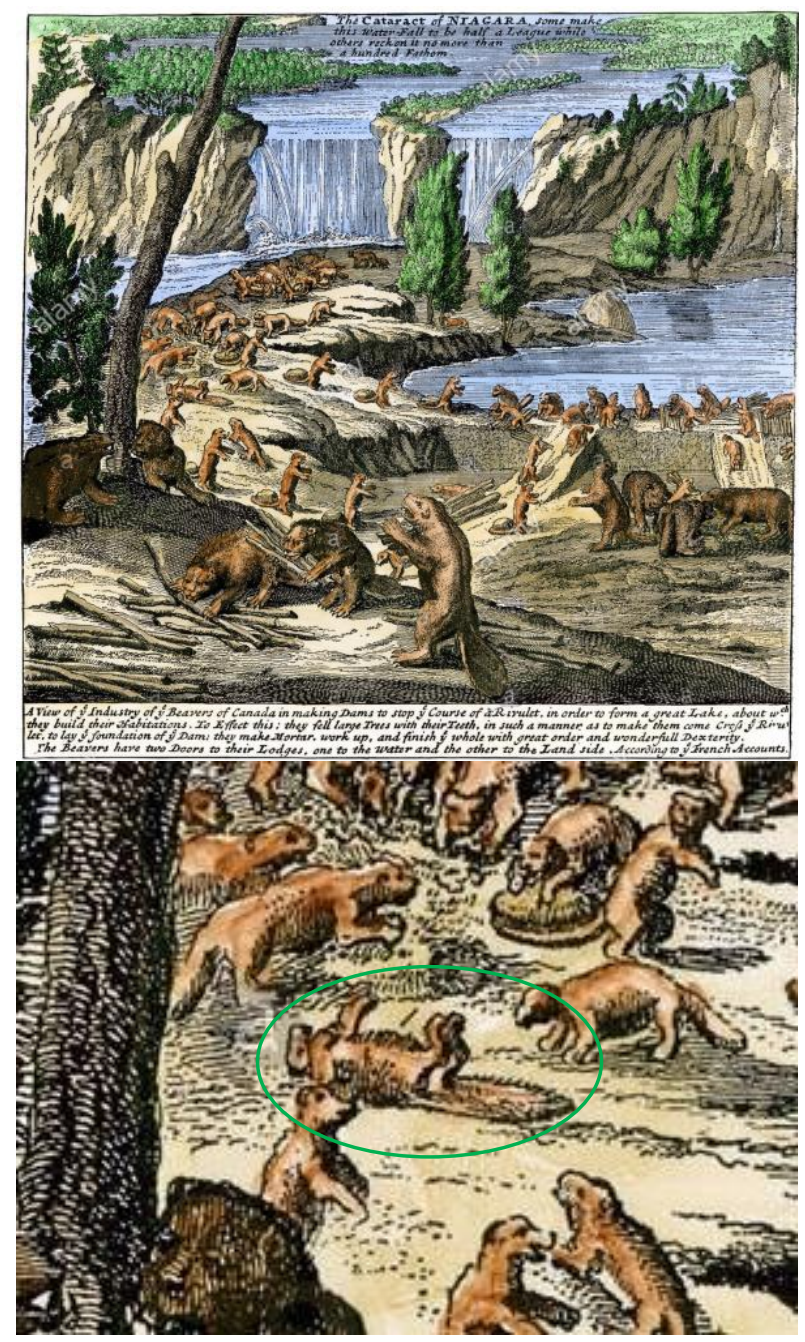

Fig. 3. Beaver community at Niagara Falls with 'exhausted beaver' detail (Herman Moll, Beaver Map, 1715, public domain).

When American beavers were introduced to Europe to increase beaver populations the American species turned out to be more aggressive and was decimating their already declining European counterparts. Ironically, castoreum turned out to be the only thing to tell the two species apart and was used to cull the American 'mistake' [12]. Historical material such as this is not just used to illustrate the errors of our ways but serves as an example of how current 'stories' that mythologize and promise the moon should be shared with caution.

In the case of beavers, however, what we can learn from them is relevant to issues we face today. Beavers, for instance, reduce fire impacts in spruce stands by creating a mosaic of habitats that act as natural firebreaks. The teeth of beavers self-sharpen [13] because their inner surface is softer than the outer enamel and wears away faster to create a sharp edge. In addition, beavers alter ecosystems by cutting trees and shrubs creating mosaics of wetlands, moist meadows, and ponds [14].

These two examples provided students with ideas for their project. They submitted a booklet with everything we know about and can learn from their organisms and formed groups around common functionalities. For example, a group could be formed around movement and the strategies their organisms used to move on solids: scales, legs, slime, etc. In their groups, they decided on prototyping one of these functional principles to demonstrate and/or illustrate a new design concept.

To help guide the students with an example, the work of Yaara Nusboim was presented [15]. Her therapy dolls are meant to channel different emotions and provide a balance of positive and negative experiences (Fig. 4). The patterns and textures of the objects are a perfect prototype example and useful when explaining concepts like selfsimilarity, repetition, composite structures, etc.

In March, students went back to the zoo and presented some of their findings alongside their prototype to a k-6 spring zoo camp. Students could take their biology to design research into their second design challenge project, if the inspiration they found was applicable to the challenge themes.

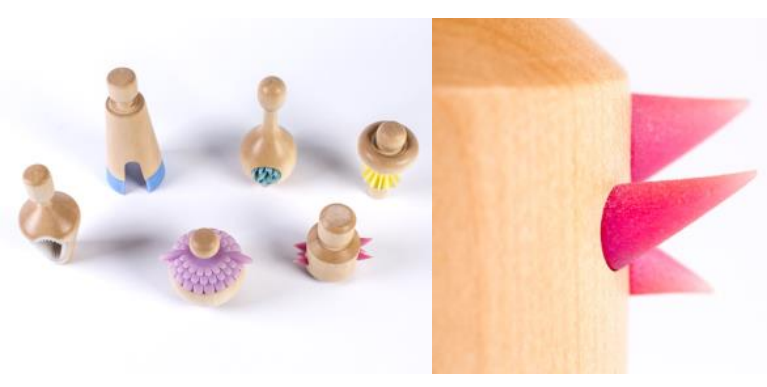

Fig. 4. Alma Therapy Dolls by Yaara Nusboim [15].

\subsection{Global Design Challenge: Challenge to Biology}

For the past 5 years, students have participated in the Biomimicry Global Design Challenge [16] as part of corner- and capstone design courses at our university. There are many examples of successful students' projects from past competitions:

- Farm (honorable mention 2017):

https://challenge.biomimicry.org/en/custom/gallery/vi ew/15867

- Foothills Flow (2020): https://innovation.biomimicry.org/team/foothills-flow/

- Windchill (2017): https://innovation.biomimicry.org/team/windchill/ 
The Biomimicry Global Design Challenge is a main project in the ENGG 523 course and is part of the challenge to biology approach. This year the challenge is connected to the Sustainable Development Goals (SDGs) and students are asked to create a nature-inspired innovation (a product, service, or system) addressing any aspect of climate change adaptation, mitigation, and reversal in any sector of the economy, that aligns with one or more of the SDGs, as outlined by the United Nations. The challenge specifically identified seven out of seventeen SDGs as being relevant to this year's theme: zero hunger, clean water and sanitation, affordable and clean energy, industry, innovation and infrastructure, sustainable cities and communities, life below water, and life on land (Fig. 5). To start identifying opportunities, students created a systems map starting with their chosen SDG and connecting the other six, indicating on sticky notes the interaction and relationships to the other SDGs (Fig. 6).
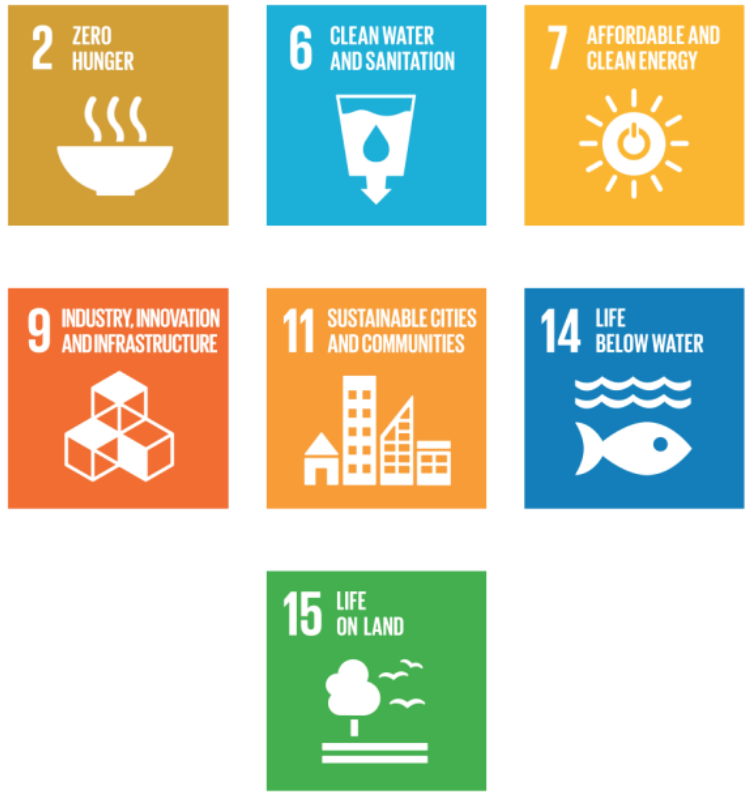

Fig. 5. The seven relevant Sustainable Development Goals for the 2020 Biomimicry Global Design Challenge.

Focussing on the interstitial spaces of their systems map, students then developed a number of design questions to start defining the challenge and to tackle an issue that can improve more than one goal. Thinking about the impact they wanted their design to have they worked on creating design questions that focused on function in context. Examples of context could include climate conditions, resource availability, temporal conditions, and interactions [16]. Once questions were generated, students practiced translating their design questions into search terms that would assist them in looking for biological models. Using the language of the biomimicry taxonomy (Fig. 7) students thought about the outcome or impact of their design question. What function do they want to solve for and rather than thinking about what they want to make, they ask themselves what they want their design to do.

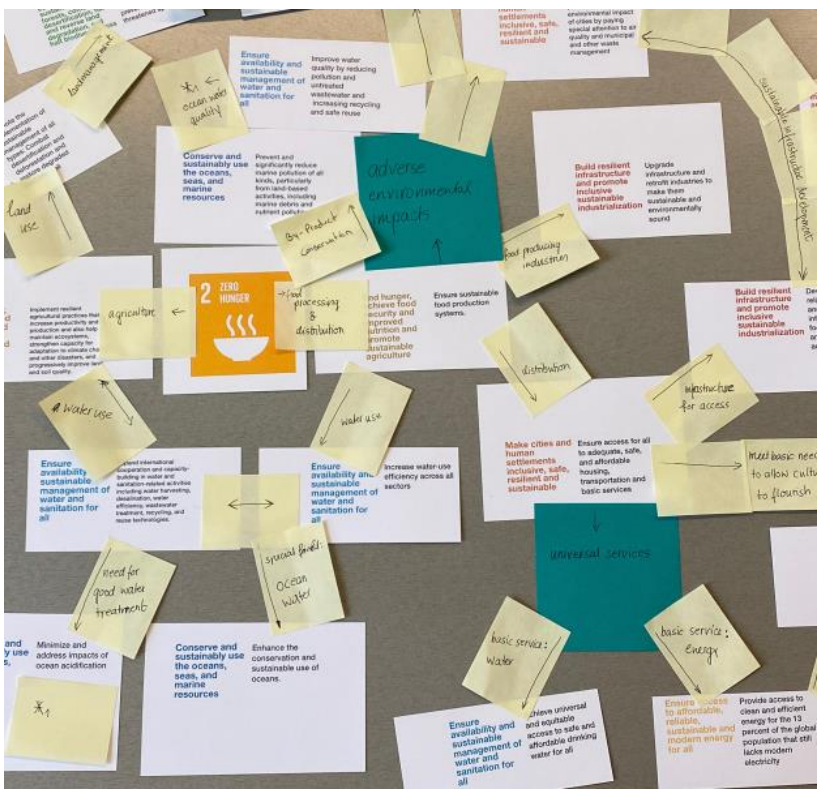

Fig. 6. Systems mapping exercise by Anna Baecke, Stephanie Weckesser, Mahima Maheshwari, Celina Spencer, and Ahsen Imran.

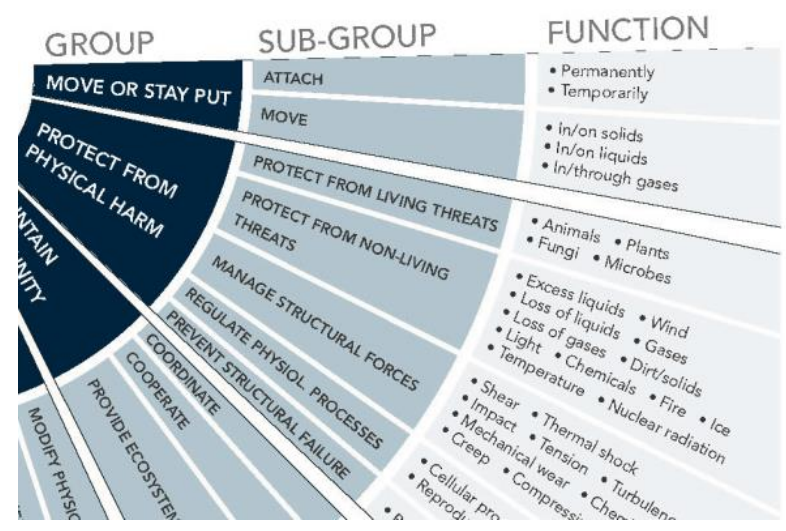

Fig. 7. Detail from the biomimicry taxonomy [17].

Having biologized their design question they might now have questions that look like this: How does nature manage impact? Two additional tools are introduced at this stage. First the website Ask Nature (asknature.org) which uses the taxonomy to structure its content. In the case of the example How does nature manage impact some Ask Nature results provide the following strategies that are used in nature to achieve a similar function:

- Plates in nacre increase toughness by interlocking

- Sutures between bony plates protect from impact and provide flexibility 
- The shell of the golden-scale snail protects from attack with a specialized tri-layered composition

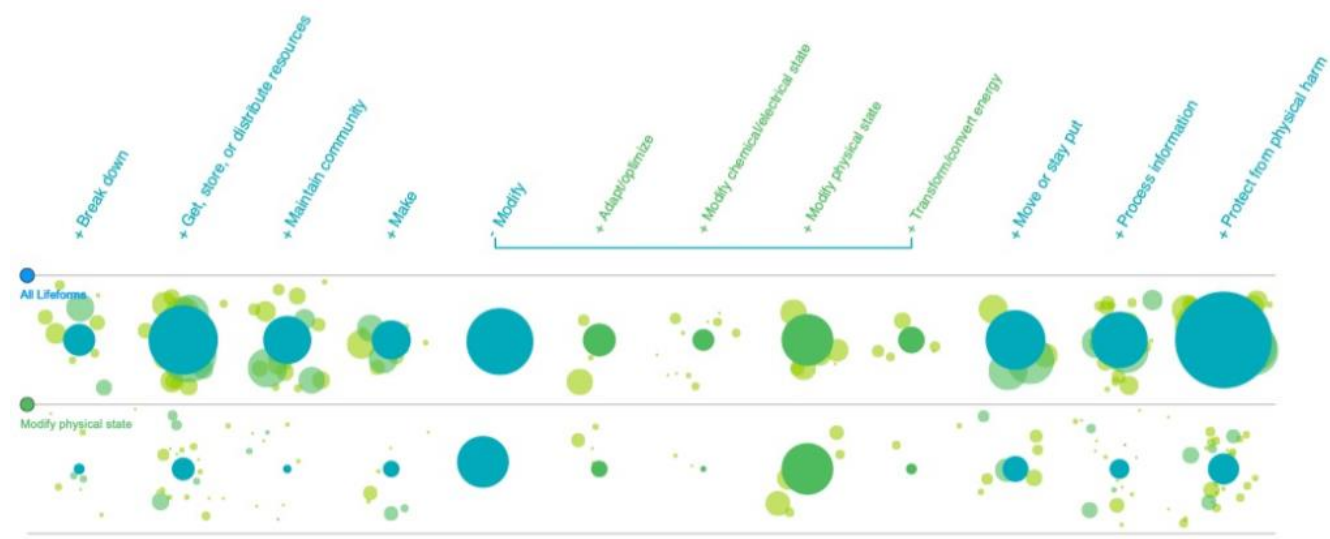

Fig. 8. Biomole tool - functional co-occurrence of biological strategies.

The second tool, Biomole (biomole.asknature.org), uses the data from the Ask Nature website but allows for functional co-occurrence [18] searches. Figure 8 combined 'modify physical state' with 'navigate'. One result stated the following: Cytoplasm of slime molds creates efficient connective networks using adaptive foraging strategies [19]. After an initial broad search for food the slime mold can adapt to concentrate its energy expenditure only in the direction of actual food 'hits'.

Students spent a number of weeks going through this iterative process, scoping and refining their design questions to match one of the many SDG sub-goals, biologizing their questions, and finding biological strategies. Students subsequently created a morphological chart based on the multitude of biological strategies that they found to generate alternatives for their design (Fig. 9).

Abstracting biological systems and transposing it to engineering followed. This is the most difficult phase and sometimes results in a biological metaphor but at times can be a quite literal translation.

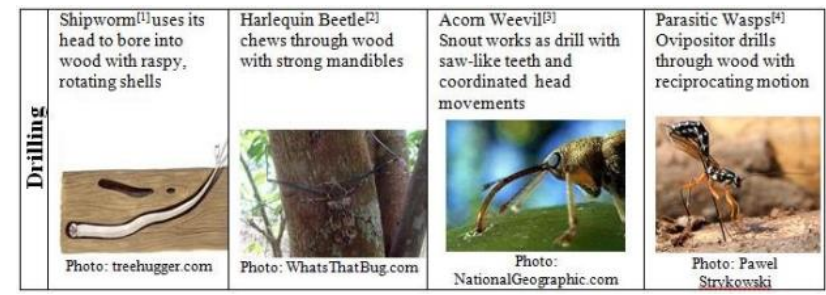

Fig. 9. Partial morphological chart for drilling [20]

Several 3D modelling sessions introduced students to tools like Fusion (Fig. 10) and Mudbox, which are better able to handle organic forms (mostly textures and patterns) compared to traditional 3D modelling software.

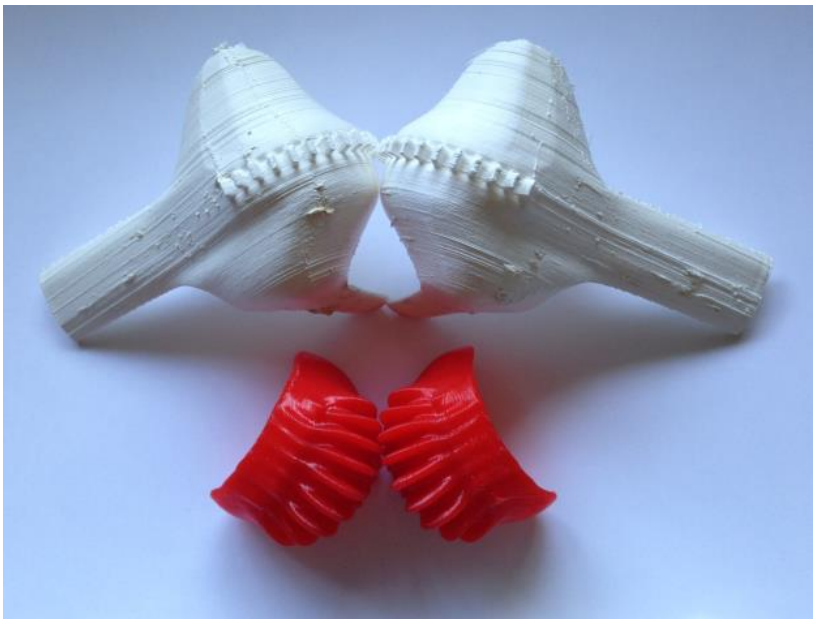

Fig. 10. Fusion modelling of Issus insect gears courtesy of C. McDonald.

For submission to the challenge students had to include evidence of how their design could mean significant environmental and/or social wins. Students used a 'living' list of patterns that can be found in nature to not only come up with a bio-inspired design but a design that included broader sustainability considerations:

- Using only the energy that is needed and relying on freely available energy

- Recycling all materials

- Being resilient to disturbances

- Optimizing rather than maximizing

- Rewarding cooperation

- Running on information

- Using chemistry and materials that are safe for living beings 
- Building using abundant resources, incorporating rare resources only sparingly

- Being locally attuned and responsive

- Using shape to determine functionality [16]

In addition, they had to discuss the limitations of their design and describe next steps, obstacles to overcome for the design to be implemented and unknown factors to be considered (e.g. materials needed, engineering tests required, etc.). Students conducted interviews with potential stakeholders to get a sense of customer product need.

\section{CONCLUSION}

In this paper we have provided an overview of the course structure for a bio-inspired fourth-year engineering technical elective. We introduced the concepts of biology to design and challenging to biology through the use of project-based learning. Firstly, after a field trips to the zoo, students took a deep dive into an organism of their choice in order to explore biology to design - students investigated everything about the organism, from history, to folklore, to anatomy to be inspired. Secondly, students completed a project which could be submitted to the Biomimicry Global Design Challenge. By considering the interconnections of the sustainable development goals, they looked for a challenge, and look to biology for inspiration to solve this challenge.

Both activities were founded in project-based learning principles, where we aimed to support the students in critical thinking and inquiry-based learning. In the final submission of the paper, we will provide further reflections on the progress of the course, as it will be near the end of the semester at that time.

\subsection{Next Steps}

The Winter 2020 version of the course at the time of writing was still ongoing. We have applied for Ethics to further investigate teaching students using bio-inspired design. Future studies will look at how students identify with the material, the most compelling aspects, and how bio-inspired design education changes their perspective on engineering design generally.

\section{Acknowledgements}

Thank you to Anna Baecke, Stephanie Weckesser, Mahima Maheshwari, Celina Spencer, Ahsen Imran, and Colin McDonald for permission to include their work.

\section{References}

[1] E. De Graaff, \& W. Ravesteijn (2001). Training complete engineers: global enterprise and engineering education.
European Journal of Engineering Education, 26 (4), pp. 419-427

[2] J. Kabo, \& C. Baillie (2009). Seeing through the lens of social justice: A threshold for engineering. European Journal of Engineering Education, 34(4), 317-325.

[3] D. Grasso \& D. Martinelli (2017). "Holistic Engineering", The Chronicle of Higher Education, 2020. Available as of February 10, 2020 from: https://www.chronicle.com/ article/Holistic-Engineering/4982

[4] M. Weissburg, C. Tovey, \& J. Yen (2010). Enhancing Innovation through Biologically Inspired Design. Advances in Natural Science.

[5] J.K.S. Nagel, \& R.M. Pidaparti (2016). "Significance, Prevalence and Implications for Bio-Inspired Design Courses in the Undergraduate Engineering Curriculum." Proceedings of the ASME 2015 International Design Engineering Technical Conference \& Computers and Information in Engineering Conference (IDERTC/CIE 2016).

[6] J.E. Mills, \& D.F. Treagust (2003). Engineering education-Is problem-based or project-based learning the answer. Australasian journal of engineering education, 3(2), 2-16.

[7] D. Kokotsaki, V. Menzies, \& A. Wiggins (2016). Projectbased learning: A review of the literature. Improving schools, 19(3), 267-277.

[8] Biomimicry 3.8. "DesignLens: Biomimicry Thinking." Available as of February 8, 2020 from https://biomimicry.net/the-buzz/resources/designlensbiomimicry-thinking/

[9] C. Suddath. (2010). “A Brief History of: Velcro,” Available as of February 8, 2020 from http://content.time.com/time/nation/article/0,8599,199688 3,00.html

[10] "na2ure", na2ure, 2020. Available as of January 27, 2020 from https://www.na2ure.com/

[11] "PIG $05049 \quad-\quad$ christienmeindertsma", Christienmeindertsma.com, 2020. Available as of January 27, 2020, from https://christienmeindertsma.com/PIG05049

[12] For more on this story see The Truth about Animals: "Lucy Cooke - TV Producer, Presenter, Author \& Explorer", Lucy Cooke, 2020. Available: as of January 27, 2020, from http://www.lucycooke.tv/\#books

[13] R. Hockauf, E. Asadi, B. Denkena, T. Grove and M. Wurz, "Grinding of riblets with "beaver tooth" multi-layer tools", Procedia CIRP, vol. 71, pp. 155-159, 2018.

[14] "Content Search - AskNature", AskNature, 2020. Available as of January 27, 2020 from https://asknature.org/?s=beaver

[15] Yaaranusboim.com, 2020. Available as of January 27, 2020 from https://www.yaaranusboim.com/

[16] T. Institute, "2020 Biomimicry Global Design Challenge", 2020 Biomimicry Global Design Challenge, 2020. 
Available as of January 27, 2020 from https://challenge.biomimicry.org/en/challenge/globaldesign-challenge-2020

[17] Biomimicry Taxonomy, Biomimmicry Toolbox, Available as of January 4, 2020 from https://toolbox.biomimicry.org/core-concepts/function-and-strategy/

[18] M. Eggermont, S. Knudsen, R. Pusch, S. Carpendale, "Biomole: Visualizing Functional Co-occurrence", IEEE VIS 2019, Oct 20-25, Vancouver. Available as of February 2, 2020 from https://sorenknudsen.com/wpcontent/uploads/2019/09/2019-IEEE-VIS-2019-PostersEggermont-Knudsen-Pusch-and-Carpendale.-BiomoleVisualizing-Functional-Co-Occurrence.pdf
[19] AskNature Team, "Cytoplasm seeks most efficient routes: Many-headed Slime - AskNature", AskNature, 2020. Available as of February 2, 2020 from https://asknature.org/strategy/cytoplasm-seeks-mostefficient-routes/\#.XjdRny0ZPUI

[20] IMECE2016-650121 LIFE CENTERED DESIGN USING MORPHOLOGICAL CHART - Scientific Figure on ResearchGate. Available as of February 3, 2020 from: https://www.researchgate.net/figure/Morphological-Chartfor-Drilling_fig3_310328184 